\title{
ESTUDO DA VIABILIDADE TÉCNICA DA UTILIZAÇÃO DE AGREGADOS RECICLADOS PROVINIENTES DE RESÍDUOS DE CONSTRUÇÕES E DEMOLIÇÕES NA PRODUÇÃO DE CONCRETO MAGRO
}

Priscila Alves da Silva Machado - priscilamachadojm@hotmail.com Universidade do Estado de Minas Gerais

Luciano da Silva Delgado- luciano766@gmail.com Universidade do Estado de Minas Gerais

André Luiz Bastos Pessoa- andreprk.bastos@ hotmail.com Universidade do Estado de Minas Gerais

Lorena Alves da Silva Machado - lorenaalves.machado@ hotmail.com Universidade do Estado de Minas Gerais 


\section{Resumo}

Os Resíduos de Construção e Demolições (RCD) proveniente de obras e reformas é um dos mais atuais desafios enfrentados pelo setor. A transformação de resíduos sólidos em novos produtos utilizáveis constitui uma solução ideal, que permite a otimização dos recursos ambientais e econômicos. O trabalho proposto tem como objetivo o estudo da viabilidade técnica e ambiental da utilização de RCD beneficiado na composição do concreto. Foi utilizado RCD de classificação A, de acordo com a CONAMA n³07/2011 com composição mista (ARM) caracterizado de acordo com a NBR15116. Posteriormente, foram produzida amostras com substituições parciais 5,10,15\% $\mathrm{m} / \mathrm{m}$ do RCD pela areia e foi realizado estudo comparativo relacionados à Resistência Mecânica e absorção de água após 28 dias. Assim, podemos que é possível de forma eficaz a utilização de RCD na confecção de concretos destinados à artefatos não estruturais.

Palavras-chave: Resíduos de construção e demolição, concreto, sustentabilidade.

\section{Introdução}

Durante o governo de Getúlio Vargas em 1940, a construção civil no Brasil teve seu maior índice de desenvolvimento efetivo, devido aos grandes investimentos estatais, gerados naquela época. Atualmente, com o crescimento emergente da classe $\mathrm{C}$ e os eventos de grande porte voltados ao país, pode-se enxergar grandes desafios na busca de materiais mais baratos e sustentáveis que sirvam de adição para o concreto utilizado nessas novas obras (MIRANDA, 2009).

O concreto de Cimento Portland deve conter cimento, água e agregados, além da possibilidade de contar com aditivos, pigmentos, fibras, agregados especiais e adições minerais, cujos empregos tornam-se cada vez mais frequentes nos concretos atuais. A proporção entre os diversos constituintes é buscada pela tecnologia do concreto para atender, simultaneamente, as propriedades mecânicas, físicas e de durabilidade requeridas por este compósito, além das características de trabalhabilidade necessárias para o transporte, lançamento e adensamento, condições estas que variam caso a caso (HELENE et al, 2010, p. 920).

Os RCDs são resíduos sólidos, inertes e são definidos como agregados, rochas, solos e areias, processados ou não. Segundo a Resolução 307 do Conselho Nacional do Meio Ambiente - CONAMA (2011), os resíduos de construção civil são: “os provenientes de construções, reformas, reparos e demolições de obras de construção civil, e os 
resultantes da preparação e da escavação de terrenos, tais como: tijolos, blocos cerâmicos, concreto, solos, rochas, metais, resinas, colas, tintas, madeiras, compensados, forros, argamassa, gesso, telhas, pavimento asfáltico, vidros, plásticos, tubulações, fiação elétrica etc., comumente denominados de entulhos de obras, caliças ou metralha" (CONAMA, 2011). Os RCDs, pela resolução CONAMA 307, são classificados em quatro classes, conforme ilustrado no Quadro1.

Quadro1 - Classificação dos Resíduos conforme resolução CONAMA n³07/2011

\section{CLASSE A}

a) De construção, demolição, reformas e reparos de pavimentação e outras obras de infraestrutura, inclusive solos provenientes de terraplenagem.

b) De construção, demolição, reforma e reparos de edificações: componentes cerâmicos (tijolos, blocos, telhas, placas de revestimento, etc.), argamassa e concreto.

c) De processo de fabricação e/ou demolição de peças pré-moldadas em concreto (blocos, tubos, meios fios, etc.) produzido nos canteiros de obra.

\section{CLASSE B}

Resíduos recicláveis para outras destinações, tais como plástico, isopor, papel, papelão, metais, vidros, madeiras, gesso e outros.

\section{CLASSE C}

Resíduos para os quais não foram desenvolvidas tecnologias ou aplicações economicamente viáveis que permitam a sua reciclagem/recuperação.

\section{CLASSE D}

Resíduos perigosos oriundos do processo de construção, tais como: tintas, solventes, óleos e outros, ou aqueles contaminados oriundos de demolições, reformas e reparos de clínicas radiológicas, instalações industriais e outros.

(Fonte: Resolução n 307 do CONAMA, 2011)

As disposições irregulares e os aterros clandestinos, ocasionados pela falta de gerenciamento, tornaram-se uma realidade no território nacional. Em 2002, com a aprovação da resolução $N^{\circ} 307$, ficaram estabelecidos critérios e procedimentos para a gestão de RCDs no Brasil (CONAMA, 2011). Por esta resolução, são atribuídas responsabilidades tanto para o poder público quanto para a iniciativa privada (PINTO et al., 2008).

A construção civil é um setor de grandes criações inovadoras, mas, ao mesmo tempo, é pouco receptivo na pesquisa. Para contornar esse problema, os projetos para esse 
segmento devem estar alinhados com novos processos ou formulações, que reduzem o tempo das construções, bem como os desperdícios. Ademais, é de fundamental importância que os projetos que, agreguem valores sem aumentar o custo e, atendam ao tripé da sustentabilidade sendo ambientalmente correto, socialmente justo e economicamente viável.

Diante do exposto, a utilização dos RCDs como matéria-prima para a produção de concreto, torna-se solução atrativa para o setor da construção civil. Para a produção de concreto utilizam-se agregados na sua composição, que por sua vez, são provenientes de fontes naturais não renováveis. Esses agregados, por serem utilizados em escala mundial e em volumes extremamente elevados tornar-se-ão escassos em um futuro próximo. Portanto, o presente trabalho teve por objetivo o desenvolvimento de novas formulações para a produção de concreto, utilizando como agregados os resíduos de construções e demolições.

\section{Metodologia}

Após pesquisa bibliográfica sobre os materiais que constituem o foco da pesquisa, a parte experimental foi realizado no laboratório de materiais de construção da Universidade do Estado de Minas Gerais - UEMG, Unidade João Monlevade-Mg, sendo que a confecção dos corpos-de-prova e suas respectivas análises seguiram a determinação da Associação Brasileira de Normas Técnicas - ABNT. Tanto na dosagem dos corpos de prova sem adição quanto nos corpos de prova com adição dos Resíduos de construções e demolições. Foi determinado um traço de acordo com as características físicas dos materiais utilizados para produção e diferenciado apenas pela quantidade de resíduos utilizados na substituição do agregado. Todas as amostras foram lavadas, secadas e caracterizadas anteriormente à realização dos experimentos.

\section{Resultados e Discursão}

\subsection{Caracterizações dos materiais}

\subsubsection{Cimento Portland}

O cimento Portland CP-IV 32 RS foi utilizado como aglomerante para mistura do concreto, conforme NBR 5736. A tabela 1 apresenta as características físicas do mesmo. 
Tabela 1: Caracterização do cimento

\begin{tabular}{|c|c|c|c|c|c|}
\hline $\begin{array}{l}\text { Tipo de } \\
\text { cimento } \\
\text { Portland }\end{array}$ & Classe & $\begin{array}{l}\text { Finura } \\
\text { (resíduo } \\
\text { na peneira } \\
\text { de } \\
75 m m(\%)\end{array}$ & $\begin{array}{l}\text { Tempo de } \\
\text { pega }(h) \\
\text { (Início- } \\
\text { Fim) }\end{array}$ & $\begin{array}{l}\text { Expansibilidade }(\mathrm{mm}) \\
(\text { A frio - A quente })\end{array}$ & $\begin{array}{l}\text { Resistência } \\
\grave{a} \\
\text { compressãa }\end{array}$ \\
\hline CPIV & $\begin{array}{l}25 \\
32\end{array}$ & $\leq 8$ & $\begin{array}{l}\geq 1 \\
\leq 12\end{array}$ & $\begin{array}{l}\leq 5 \\
\leq 5\end{array}$ & $\begin{array}{l}\geq 25,0 \\
\leq 32,0\end{array}$ \\
\hline
\end{tabular}

(Fonte: Associação Brasileira de Cimento Portland)

\subsubsection{Agregado miúdo: Areia}

A areia quartzosa utilizada neste estudo foi proveniente do Rio Piracicaba- MG. Através de ensaios de granulometria, massa específica e massa unitária, na tabela 2 , podem-se visualizar características físicas da mesma [3].

Tabela 2: Características do agregado miúdo (areia)

\begin{tabular}{l|l}
\hline Característica & Valores \\
\hline Módulo de finura & \\
Massa específica & 2,52 \\
Massa unitária & $2,57 \mathrm{~g} / \mathrm{cm}^{3}$ \\
\hline
\end{tabular}

(Fonte: Próprios autores)

\subsubsection{Agregado graúdo: Brita}

O agregado graúdo utilizado neste trabalho é de origem metamórfica (brita de gnaisse). A tabela 3 mostra a caracterização da brita utilizada neste trabalho [3].

Tabela 3: Características do agregado graúdo (brita)

\begin{tabular}{l|l}
\hline Característica & Valores \\
\hline Dimensão máxima característica & $12,5 \mathrm{~mm}$ \\
Massa específica & $2,78 \mathrm{~g} / \mathrm{cm}^{3}$ \\
Massa unitária & $1,80 \mathrm{~g} / \mathrm{cm}^{3}$ \\
\hline
\end{tabular}




\subsubsection{Resíduos de Construcão e Demolicões}

Os Resíduos de Construção e Demolição foram recolhidos de obras de reforma da cidade de João Monlevade-MG e passaram por processo de beneficiamento antes de serem incorporados ao concreto, resumindo nas etapas de: Triagem, britamento, moagem e secagem, de acordo com a NBR 15116.

O RCD foi submetido a ensaios de caracterização cujos resultados são apresentados na tabela 4 a seguir:

Tabela 4: Características do RCD

\begin{tabular}{l|l}
\hline Característica & Valores \\
& \\
\hline Massa específica & $1,98 \mathrm{~g} / \mathrm{cm}^{3}$ \\
Massa unitária & $2,05 \mathrm{~g} / \mathrm{cm}^{3}$ \\
\hline
\end{tabular}

(Fonte: Próprios Autores)

\subsection{Produção de concreto magro}

\subsubsection{Estudo do traco}

A partir das características estudadas nos materiais, foi calculado um traço base para um concreto de $25 \mathrm{MPa}$, de acordo com o Método do ABCP, onde originou-se a proporção volumétrica de: 1:1,7:1,8: 0,5 a/c (cimento, areia, brita, relação água cimento).

\subsubsection{Producão de Amostras}

Com o objetivo de estudar a resistência mecânica do concreto com utilização de resíduos de construção e demolições (RCDs) em sua composição foram substituídos, parcialmente, o agregado miúdo (areia) nas proporções de $0 \%, 5 \%, 10 \%$ e $15 \% \mathrm{~m} / \mathrm{m}$. A confecção do concreto foi realizada com o auxílio de uma betoneira de queda livre, sendo que os agregados de concretos foram os últimos componentes a serem adicionados à mistura. Posteriormente, foram confeccionados 36 corpos de prova cilíndricos nas dimensões de $10 \mathrm{~cm}$ de diâmetro por $20 \mathrm{~cm}$ de altura, conforme a figura. Os ensaios foram realizados aos 7,14 e 28 dias de cura submersa, conforme determinação da NBR 7215.

Para a caracterização mecânica, os corpos de prova foram capeados e, posteriormente, submetidos a ensaios mecânicos, que foram realizados em uma máquina de ensaios universal. Este equipamento fornece a força máxima de ruptura e a curva tensãodeformação, as quais foram utilizadas para calcular a resistência mecânica e submetidas 
a ensaios de absorção de água, de acordo com a NBR NM53, com o objetivo de monitorar poros permeáveis nos agregados.

Neste tópico apresentam-se os resultados obtidos nos ensaios mecânicos mencionados anteriormente. Estes dados permitem avaliar as propriedades de resistência do concreto com agregados de resíduos de construção e demolição (RCD). A figura 1, mostra os dados referentes ao ensaio de resistência à compressão axial. Pode ser observado que o menor valor de resistência à compressão ocorreu no corpo de prova de concreto de $15 \% \mathrm{~m} / \mathrm{m}$ substituição de agregado miúdo por RCD, e o maior valor ocorreu no concreto com substituição parcial de $10 \%$ adição de agregado miúdo por agregado de RCD.

\section{Figura 1- Dados referentes ao ensaio de resistência à compressão axial}

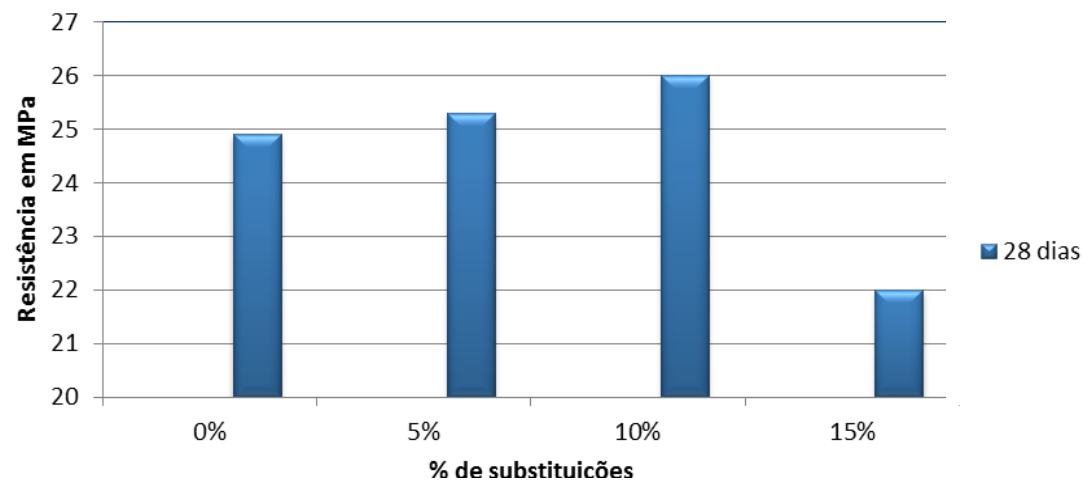

(Fonte: Próprios Autores)

$\mathrm{Na}$ figura 2, referente ao ensaio de resistência à tração por compressão diametral, pode ser observado que ao aumentar a quantidade de RCD incorporado a resistência a compressão diametral diminui.

Figura 2- Dados referentes ao ensaio de resistência a compressão diametral

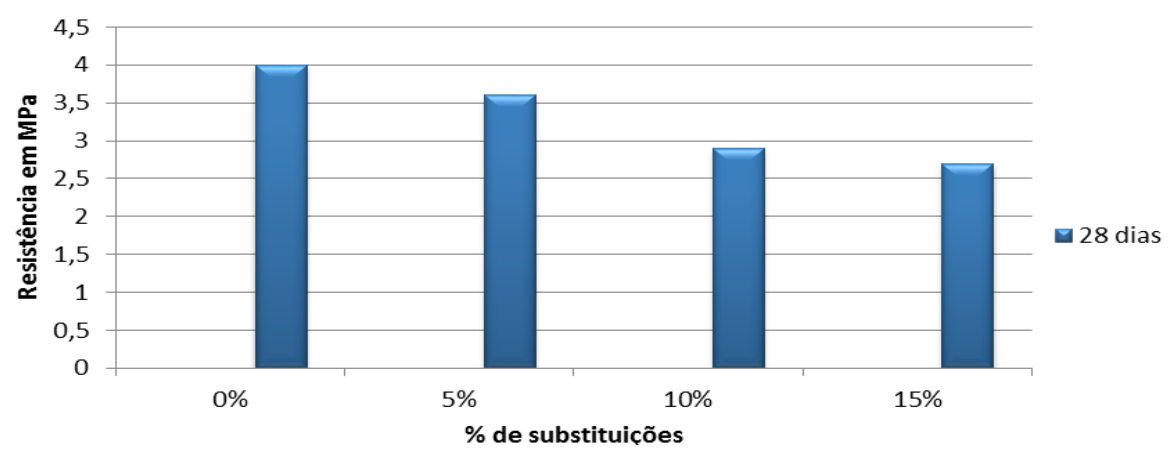

(Fonte: Próprios Autores)

A figura 3 apresenta os dados referentes ao ensaio de resistência à tração na flexão. Pode ser observado que o menor valor de resistência ocorreu no bloco de concreto produzido de $15 \% \mathrm{~m} / \mathrm{m}$ de substituições de RCD e o maior valor ocorreu no 
concreto fabricado com substituição parcial de $10 \% \mathrm{~m} / \mathrm{m}$ de agregado miúdo por agregado de RCD.

Figura 3- Dados referentes ao ensaio de tração por flexão

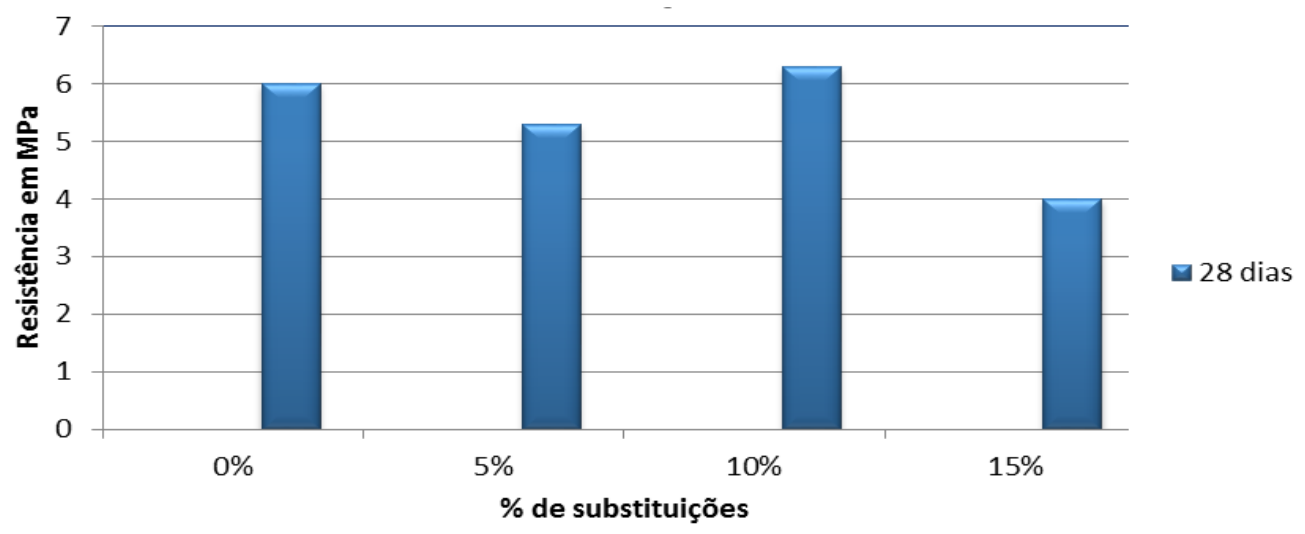

(Fonte: Próprios Autores)

A figura 4 apresenta os dados referentes à absorção de água. $\mathrm{O}$ ensaio foi realizado em apenas corpos de prova com cura de 28 dias. Pode ser observado no gráfico que os valores estão bem equiparados e que houve um aumento entre os percentuais obtidos.

Figura 4- Dados referentes ao ensaio de absorção de água

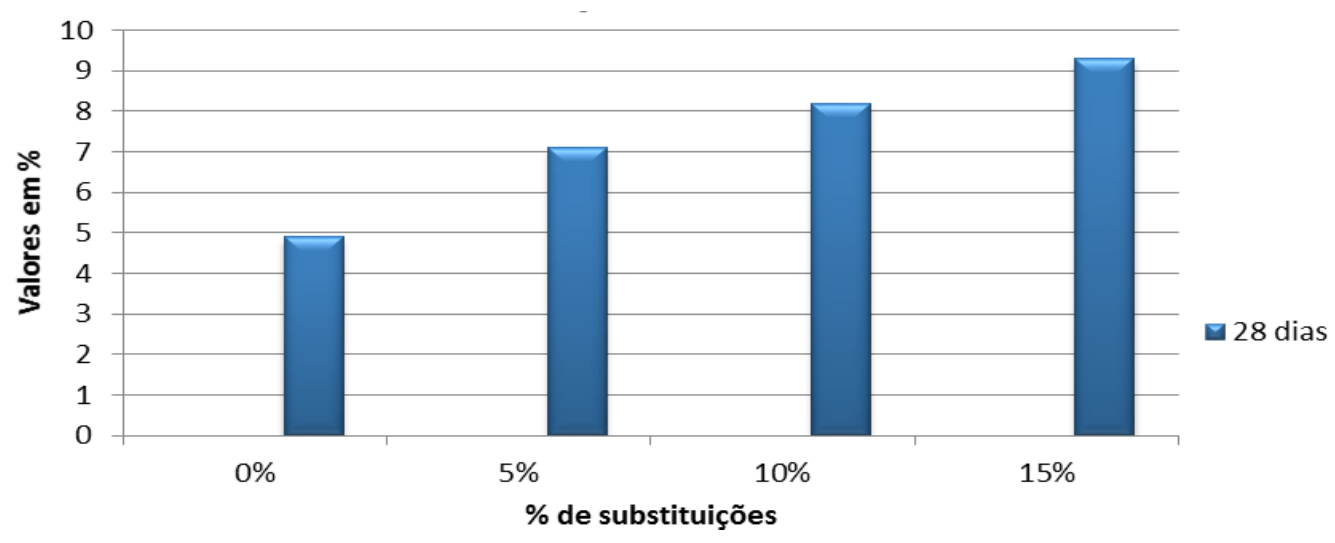

(Fonte: Próprios Autores)

\section{Conclusão}

Segundo testes realizados em laboratório com 36 corpos de prova nas condições de substituição: $0 \%, 5 \%, 10 \%$ e $15 \%$ de RCD, o emprego de resíduos de construção e demolições para formulação de concretos é tecnicamente viável. Sendo que o concreto 
com substituição de $10 \%$ de RCD apresentou a melhor característica mecânica, não variando muito do corpo de prova usado como referência.

Do ponto de vista de aplicação e considerando os resultados obtidos, em particular com relação à resistência mecânica, os traços obtidos com a substituição de agregados de RCD podem ser aplicados na indústria da construção civil para a fabricação de artefatos não estruturais referentes à resistência mecânica. Para trabalhos futuros, torna-se interessante o estudo do concreto em longo tempo.

\section{REFÊRENCIAS}

[1] ABCP, Associação Brasileira do Concreto Portland - Disponível em: http://www.abcp.org.br/. Acesso em 15 de abril de 2016.

[2] ABEPET. Associação Brasileira dos Fabricantes de Embalagens PET. Disponível em: www.abepet.com.br. Acesso em 22 de setembro de 2016.

[3] ABNT - Associação Brasileira de Normas Técnicas. NBR 5738 - Procedimento para moldagem e cura de corpos-de-prova. ABNT, Rio de Janeiro, 2003.

[4] ABNT - Associação Brasileira de Normas Técnicas. NBR 5739: Concreto - Ensaios de compressão de corpos-de-prova cilíndricos. ABNT, Rio de Janeiro, 2007.

[5] ABNT - Associação Brasileira de Normas Técnicas. NBR 7222- Concreto e argamassa - Determinação da resistência à tração por compressão diametral de corpos de prova cilíndricos. ABNT, Rio de Janeiro, 2011.

[6] ABNT - Associação Brasileira de Normas Técnicas. NBR 8522: Concreto Determinação do módulo estático de elasticidade à compressão e Diagrama TensãoDeformação - Método de Ensaio. Rio de Janeiro, 2008.

[7] ABNT - Associação Brasileira de Normas Técnicas. NBR 12142 / MB 3483:

Concreto - Determinação da resistência à tração na flexão em corpos de prova (Procedimento). Rio de Janeiro, 1991.

[8] ABNT - Associação Brasileira de Normas Técnicas. NBRNM 52: Agregados Determinação da massa específica e massa específica aparente. Rio de Janeiro, 2009. [9] ABNT - Associação Brasileira de Normas Técnicas. NBRNM 248: Agregados determinação da composição granulométrica. Rio de Janeiro, 2003.

[9] ABNT - Associação Brasileira de Normas Técnicas. NBR 15116: Agregados reciclados de resíduos sólidos da construção civil- Utilização em pavimentação e preparo de concreto sem função estrutural- Requisitos Rio de Janeiro, 2004. 
[10] Conselho Nacional do Meio Ambiente (CONAMA). Resolução n ${ }^{\circ}$ 307, de 05 de julho de 2002: Estabelece diretrizes, critérios e procedimentos para a gestão dos resíduos da construção civil. Diário Oficial da União, Brasília, DF, 17 jul. 2002.

[11] HELENE, P.; ANDRADE, T. Concreto de Cimento Portland. In: ISAIA, Geraldo Cechella. Materiais de Construção Civil e Princípios de Ciência e Engenharia de Materiais. São Paulo: Ibracon, 2010. V2, Cap. 27, pp. 905-944.

[12] MIRANDA, F. R.; ANGUlO, S. C.; CARELI, E. D. A Reciclagem de Resíduos de Construção e Demolição no Brasil: 1986-2008. Ambiente Construído, Porto Alegre, v. 9, n. 1, pp. 57-71, jan./mar. 2009.

[13] PINTO, T. P.; GONZÁLES, J. L. R. Manejo e Gestão de Resíduos da Construção Civil. Como implantar um Sistema de Manejo e Gestão dos Resíduos da Construção Civil nos Municípios. Brasília: Caixa Econômica Federal; Ministério das Cidades, Ministério do Meio Ambiente, 2005. v. 1, .198p. 